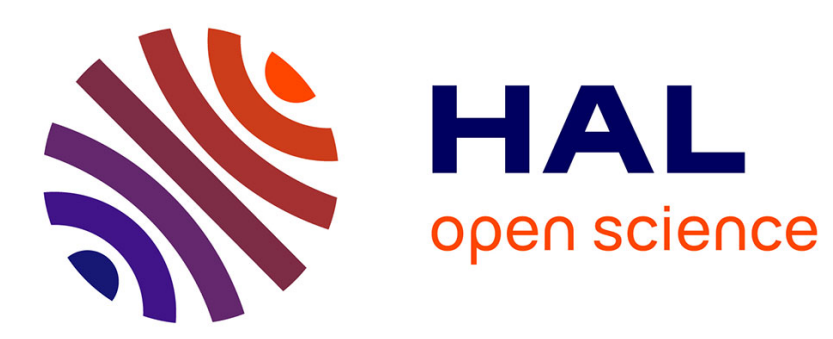

\title{
Numerical Assessment for Impact Strength Measurements in Concrete Materials
}

Werner Riedel, Nobuaki Kawai, Ken-Ichi Kondo

\section{To cite this version:}

Werner Riedel, Nobuaki Kawai, Ken-Ichi Kondo. Numerical Assessment for Impact Strength Measurements in Concrete Materials. International Journal of Impact Engineering, 2008, 36 (2), pp.283. 10.1016/j.ijimpeng.2007.12.012 . hal-00548163

\section{HAL Id: hal-00548163 https://hal.science/hal-00548163}

Submitted on 19 Dec 2010

HAL is a multi-disciplinary open access archive for the deposit and dissemination of scientific research documents, whether they are published or not. The documents may come from teaching and research institutions in France or abroad, or from public or private research centers.
L'archive ouverte pluridisciplinaire HAL, est destinée au dépôt et à la diffusion de documents scientifiques de niveau recherche, publiés ou non, émanant des établissements d'enseignement et de recherche français ou étrangers, des laboratoires publics ou privés. 


\section{Accepted Manuscript}

Title: Numerical Assessment for Impact Strength Measurements in Concrete Materials

Authors: Werner Riedel, Nobuaki Kawai, Ken-ichi Kondo

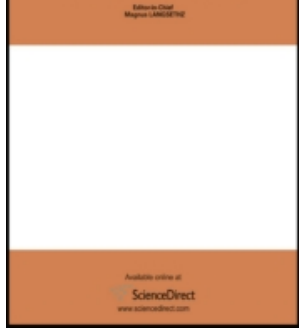

PII: $\quad$ S0734-743X(08)00077-8

DOI: $\quad$ 10.1016/j.jijmpeng.2007.12.012

Reference: IE 1583

To appear in: International Journal of Impact Engineering

Received Date: 27 June 2007

Revised Date: 19 December 2007

Accepted Date: 19 December 2007

Please cite this article as: Riedel W, Kawai N, Kondo K. Numerical Assessment for Impact Strength Measurements in Concrete Materials, International Journal of Impact Engineering (2008), doi: 10.1016/j.jïmpeng.2007.12.012

This is a PDF file of an unedited manuscript that has been accepted for publication. As a service to our customers we are providing this early version of the manuscript. The manuscript will undergo copyediting, typesetting, and review of the resulting proof before it is published in its final form. Please note that during the production process errors may be discovered which could affect the content, and all legal disclaimers that apply to the journal pertain. 


\title{
Numerical Assessment for Impact Strength Measurements in Concrete Materials
}

\author{
Werner Riedel $^{*+}$, Nobuaki Kawai ${ }^{* *}$, Ken-ichi Kondo ${ }^{* * *}$ \\ *Fraunhofer Institut für Kurzzeitdynamik, Ernst-Mach-Institut, Eckerstraße 4, D-79104, Freiburg, Germany \\ ${ }^{* *}$ Center for Urban Earthquake Engineering, Tokyo Institute of Technology \\ ${ }^{* * *}$ Materials \& Structures Laboratory, Tokyo Institute of Technology, 4259 Nagatsuta,, Yokohama 226-8503, Japan
}

\begin{abstract}
Measurement of dynamic strength of concrete at impact relevant strain rates and pressures is the purpose of the described study. Therefore, an experimental design of direct planar impact experiments with longitudinal and transverse strain gauges is analyzed in predictive hydrocode simulations using an elastic-plastic damage model for concrete. The calculations and first experimental results on mortar show decreasing phase velocities of stress waves both in longitudinal and lateral gauges. The model clearly associates it with the onset of damage, possibly interpreted as a failure wave. Numerical analysis is furthermore used to compare a monolithic target block to a thoroughly assembled concrete sample in order to include flat gauges in the material. The planned experimental procedure to derive wave speeds, particle velocities and strain rates from stress measurements is anticipated and validated on the basis of simulated gauge signals. The most important finding is the prediction and first experimental confirmation that concrete ultimate strength and damaged yield stress can be derived at strain rates in the order of $10^{4} / \mathrm{s}$ from the proposed type of experiments. This technique promises new insight into the strength and failure processes of concrete in the challenging loading region around the characteristic minimum of its shock particle velocity relationship.
\end{abstract}

Keywords: Concrete strength, pore compaction, strain rate, failure wave, yield surface, damaged material.

${ }^{+}$Corresponding author. Tel.: +49 76289050 692; fax: +49 76289050677 .

E-mail address: riedel@emi.fraunhofer.de 


\section{Introduction}

\subsection{Dynamic Strength Analysis and Modeling Approaches}

Analysis and modeling of concrete impact behavior has been an active research area over the last decades. A number of authors have measured the longitudinal stress wave behavior ranging from low velocities up to strong shock loading as high as $20 \mathrm{GPa}$ pressure and strain rates of $10^{6} / \mathrm{s}$. Figure 1 gives an overview of available literature data by Gregson [14], Grady [11],[12],[13], Kipp and Chhabildas [24], Ockert [28], Ishiguchi [21], Tsembelis [36],[37],[38] Gebbeken [9], Riedel [31],[32]. The dashed lines point out the remarkable drop in the compression wave velocity $U_{s}$, or better phase velocity $c_{p}$ [41], from particle velocities $u_{p}$ between 50 and $300 \mathrm{~m} / \mathrm{s}$. The reduction from the acoustic $1 \mathrm{D}$ strain longitudinal sound speeds above $4000 \mathrm{~m} / \mathrm{s}$ to less than $2000 \mathrm{~m} / \mathrm{s}$ for conventional strength concrete [24],[32] is generally assigned to the compaction of the concrete pores and the onset of damage. Higher loading intensities ( $u_{p}$ above $>400 \mathrm{~m} / \mathrm{s}$ ) override the energy consumption of these processes. As the impedances of aggregate and mortar differ most in this regime, measurements and scattering are very challenging around this minimum.

Moreover, concrete exhibits a complex distortional behavior. Figure 1, right, shows equivalent stresses at failure loads as function of hydrostatic pressures $\mathrm{p}$ for four different concrete qualities between $35 \mathrm{MPa}$ and $140 \mathrm{MPa}$ compressive strength. Equation (1) defines the equivalent stress $\sigma_{\mathrm{eq}}$ as function of the principal stresses $\sigma_{1}, \sigma_{2}, \sigma_{3}$ for general load cases. In the special case of cylindrical symmetric loading with $\sigma_{2}=\sigma_{3}$, it is equal to the stress difference $\Delta \sigma$.

$$
\begin{gathered}
\sigma_{e q}=\sqrt{\frac{1}{2}\left[\left(\sigma_{1}-\sigma_{2}\right)^{2}+\left(\sigma_{2}-\sigma_{3}\right)^{2}+\left(\sigma_{3}-\sigma_{1}\right)^{2}\right]^{c y l . ~ s y m m . ~}}=\left|\sigma_{1}-\sigma_{2}\right|=\Delta \sigma=2 \tau \\
p=-\frac{1}{3}\left(\sigma_{1}+\sigma_{2}+\sigma_{3}\right)
\end{gathered}
$$

Before failure initiation inelastic stresses start for conventional concrete at about $85 \%$ of the strength in uniaxial tension and above $35 \%$ in unixial compression. Irreversible pore compaction is observed under hydrostatic loading. After failure shear stresses are only supported under confined conditions but are still substantial for example during penetration into thick concrete targets [17]. A number of models (e.g. Chen [5], Riedel [31], Itoh et al. [20], Gebbeken, Ruppert [10], Malvar [25]) describe elasticity, hardening up to failure and post-failure shear resistance by three limit surfaces, as shown in figure 2. A 
point of discussion remains the closure of the elastic surface towards high hydrostatic pressure by 'cap' formulations.

Strain rate dependence on these limit surfaces is so far mostly measured along the lines of uniaxial compressive and tensile stresses $\sigma_{\mathrm{eq}}= \pm 3 \mathrm{p}$ (dashed lines in figure 4, right): Dynamic experiments loading concrete specimens in dynamic uniaxial compression can reach strain rates of several 100/s with strength increase factors up to 2.5 (Bischoff [1]). Split Hokinson-Bar measurements on scaled concrete or mortar can reach 1700/s and increase factors up to 4 (Grote [15]). The strain rate dependence in uniaxial tension, for example using a Hopkinson-Bar in spallation configuration, is even stronger with dynamic strength increase factors of 4-12 at maximum strain rates from 50/s to 120/s, (Klepaczko [22], Schuler [33]).

Shock waves generate strain rates from $10^{4}$ to $10^{6} / \mathrm{s}$. Dynamic shear strength of brittle materials under shock loading has been measured and simulated mainly for glass and ceramics by a number of authors, e.g. Kanel [22], Brar[4], Clifton [6], Espinosa [7],[8], Millet, Rosenberg [26], Bourne [3]. By mounting flat stresses gauges in normal and lateral direction into specimens subjected to plate impact, shear stresses $\tau$ of the materials are measured. Planar stress and shock waves are compressing in uniaxial strain with $\sigma_{\mathrm{eq}}= \pm 3 \mathrm{p}(1-2 v) /(1+v)$ in the elastic regime (broken line in figure 2, right). Higher loading with permanent deformation causes deviation from this line along the failure surface towards higher pressures. Time delayed failure has been shown to result in a two-wave structure referred to as 'failure wave', which is especially apparent in the lateral stress signal. Rise in longitudinal strain has been observed with the passing of the failure front, while lateral strains remain negligible [26]. A distinct influence on the propagation of the failure wave by additional target assembly surfaces was reported by Bourne [3].

Micro-concrete and mortar materials have been studied with stress gauges in the material by Tsembelis [37],[39] and Grote [16] to derive deviatoric strength and failure. Grote [16] reports the limit of elastic longitudinal and transverse stresses to be at $167 \mathrm{~m} / \mathrm{s}$ for PMMA plate impact which corresponds to $130 \mathrm{MPa}$ compressive stress. He shows that stronger loading does not provide shear stresses above the theoretical elastic limit. Tsembelis measures the stress differences $\Delta \sigma$ from 0.4 to $1.45 \mathrm{GPa}$ for higher longitudinal stresses from 0.8 up to $6 \mathrm{GPa}$. They are almost identical for micro-concrete and cement paste.

In this work the impact shear strength analysis method is applied to large mortar and concrete samples in order to measure strength and failure at very high strain rates. The $200 \mathrm{~mm}$ caliber allows parallel use of axial and lateral stress gauges at the same distance from the impact plane. Numerical 
simulation is used before and after testing to predict and analyze stress and damage evolution in monolithic and assembled concrete targets.

\subsection{Configuration}

The experimental configuration under development by Kawai [41] is shown in figures 3 and 4. A Ushaped aluminium projectile (diameter $200 \mathrm{~mm}$, bottom plate thickness $25 \mathrm{~mm}$, collar thickness $15 \mathrm{~mm}$, overall length $100 \mathrm{~mm}$ ) is impacted with its flat bottom onto a concrete block of overall dimension $\mathrm{L}=100 \mathrm{~mm}, \mathrm{~B}=100 \mathrm{~mm}, \mathrm{H}=185 \mathrm{~mm}$. In the present paper impact velocities of $170 \mathrm{~m} / \mathrm{s}$ are considered, the impact facility is designed to allow up to $280 \mathrm{~m} / \mathrm{s}$. Polyvinylidene fluoride (PVDF) stress gauges 1,2 and 3 with measurement areas of $6 \times 6 \mathrm{~mm}$ are placed in longitudinal direction at 10, 20 and 30mm beneath the impact surface along the axis of impact. Gauge 4 measures transverse stresses in the same plane as number 1 but is located $70 \mathrm{~mm}$ off the symmetry axis. The concrete target is assembled from a number of precisely ground blocks and tiles to mount the gauges between them. Tiles Ia, Ib, Ic measure each 10x100x100mm and are backed by block II (70x100x100mm). Blocks III (100x100x20mm) and IV $(100 \times 100 \times 65 \mathrm{~mm})$ are attached below the resulting cube. The blocks are precisely rectified and connected with a fine film of epoxy resin thinner than $200 \mu \mathrm{m}$. An additional block V of concrete is added onto the assembly.

The following questions arise in context with the experimental configuration:

1. Does the assembly of the concrete target influence the measurement of longitudinal and transverse stresses in comparison to a monolithic sample?

2. When and to which extent does the assembly alter the damage evolution and propagation?

3. Can be assumed that the lateral stress measurements in gauge position 4 are the same as in position 1, where the longitudinal stress is taken?

4. Which interpretation will be possible form the stress gauge data?

To clarify these points the experimental configuration is numerically modeled in the following. 


\section{Numerical Simulation Approach}

\subsection{Lagrangian Hydrocode}

Basis of the simulations is the finite difference scheme of the commercial hydrocode AUTODYNV6.0 [27], which also incorporates finite element and smooth particle hydrodynamics discretisations. The differential equations $(3 \mathrm{a}, \mathrm{b}, \mathrm{c})$ are derived from conservation of mass, momentum and energy in Lagrangian referential (moving with the material) and solved together with the equation of state (6),(11) linking pressure $p$, density $\rho$ and internal energy e. Stresses and strains a decomposed into hydrostatic pressure $\mathrm{p}$ and deviatoric stresses $\mathrm{S}_{\mathrm{ij}}$. In (4a) compressive pressures are defined positive as well tensile stresses $\sigma_{\mathrm{ij}}, \mathrm{S}_{\mathrm{ij}}$. The Jaumann tensor of deviatoric stress rates (4b) is used to integrate the strength portion of material behavior for small strain increments $d \varepsilon_{\mathrm{ij}} / d t(5 a)$ per time step. Stress contributions from rotation rates $\mathrm{dr}_{\mathrm{ij}} / \mathrm{dt}(5 \mathrm{~b})$ are eliminated to obtain an objective material description, independent of the choice of coordinate system and rigid body motions. Explicit time integration fulfilling the CourandFriedrich-Levy criterion yields stability of the numerical scheme. This combination of stress and strain referentials and time integration is often called 'update Lagrange-Jaumann scheme' and allows consistent large strain material description when integrated over several time steps. Coordinates $\mathrm{x}_{\mathrm{i}}$, velocities $\mathrm{v}_{\mathrm{i}}$ and accelerations are nodal variables in the computational grid, while material properties such as mass, pressure, deviatoric stresses, internal energy are evaluated in the cell centre.

$$
\begin{gathered}
\frac{D \rho}{D t}+\rho \frac{\partial v_{i}}{\partial x_{i}}=0 \\
\rho \frac{D v_{i}}{D t}=-\frac{\partial p}{\partial x_{i}}+\frac{\partial S_{j i}}{\partial x_{j}}+\rho f_{i} \\
\rho \frac{D e}{D t}=\rho \dot{q}-p \frac{\partial v_{i}}{\partial x_{i}}+S_{j i} \frac{\partial v_{i}}{\partial x_{j}} \\
\sigma_{i j}=S_{i j}-p \delta_{i j} \quad \dot{S}_{i j}=\underbrace{S_{i j} \dot{r}_{j k}+S_{k j} \dot{r}_{i k}}_{\text {rotation correction }}+G\left(\dot{\varepsilon}_{i j}-\frac{1}{3} \delta_{i j} \dot{\varepsilon}_{k k}\right) \\
\dot{\varepsilon}_{i j}=\frac{1}{2}\left(\frac{\partial v_{i}}{\partial x_{j}}+\frac{\partial v_{j}}{\partial x_{i}}\right) \quad \dot{r}_{i j}=\frac{1}{2}\left(\frac{\partial v_{i}}{\partial x_{j}}-\frac{\partial v_{j}}{\partial x_{i}}\right)
\end{gathered}
$$




\subsection{Constitutive Models for Aluminium and Epoxy}

Both materials are described using an equation of state in Mie-Grüneisen form (6a) with a Hugoniot reference curve $\mathrm{p}_{\mathrm{H}}(\rho)$ and the Grüneisen coefficient $\Gamma=\mathrm{V}(\partial \mathrm{p} / \partial \mathrm{e})_{\mathrm{V}}$ to extrapolate to general material states. The Aluminium Hugoniot curve is expressed in terms of shock velocity $U_{s}$ and particle velocity $u_{p}$ using the linear approximation with the material parameters bulk sound speed $c_{B}$ and slope $S(6 b)$. A polynomial formulation (6c) is chosen for the Epoxy. The equation of state parameters are summarized in the appendix table III, left columns.

$$
\begin{gathered}
p(\rho, e)=\Gamma \rho e+p_{H}\left[1-\frac{1}{2} \Gamma\left(\frac{\rho}{\rho_{0}}-1\right)\right] \\
p_{H}(\eta)=\rho_{0} c_{B}{ }^{2} \frac{\eta(1+\eta)}{[1-\eta(S-1)]^{2}} \quad p_{H}(\eta)=A_{1} \eta+A_{2} \eta^{2}+A_{3} \eta^{3} \quad \text { with } \eta=\frac{\rho}{\rho_{0}}-1
\end{gathered}
$$

Elastic stress rates $\mathrm{dS}_{\mathrm{ij}} / \mathrm{dt}$ are derived via Hooke's law in Jaumann's formulation (4b) from strain and rotation rates $(5 a, b)$. Steinberg and Guinan's [34],[35] model describes the Aluminium with the shear modulus G depending on pressure and temperature. A constant shear modulus is assumed for Epoxy.

$$
\begin{gathered}
G=G_{0}\left[1+\left(\frac{G_{p}^{\prime}}{G_{0}}\right) \frac{p}{\eta^{1 / 3}} \beta+\left(\frac{G_{T}^{\prime}}{G_{0}}\right)(T-300)\right] \\
f\left(\sigma_{i j}\right)=F\left(\sigma_{i j}\right)-Y=0 \quad F\left(\sigma_{i j}\right)=\sigma_{e q} \\
d \varepsilon_{i j}^{p}=d \lambda \frac{\partial f}{\partial \sigma_{i j}} \quad \varepsilon_{e q}^{p}=\sqrt{\frac{2}{3} \varepsilon_{i j}^{p} \varepsilon_{i j}^{p}} \quad \Delta \varepsilon_{e q}^{p}=\frac{\sigma_{i j}^{p}}{3 G}=\frac{\sigma_{e q}^{e}-Y}{3 G} \\
Y=Y_{0}\left[1+\left(\frac{Y_{p}^{\prime}}{Y_{0}}\right) \frac{p}{\eta^{1 / 3}}+\left(\frac{G_{T}^{\prime}}{G_{0}}\right)(T-300)(1+\beta \varepsilon)^{n}\right]
\end{gathered}
$$

Elastic stresses are limited by the flow rule (8) based on the von Mises equivalent stress $\sigma_{\text {eq }}(1)$. The flow rule (9a) is associated with the flow surface, so that plastic strain increments are calculated using 'radial return' (9c). Steinberg and Guinan's model describes the Aluminium flow surface depending on isotropic strain hardening, pressure and temperature (10). All material parameters are summarized in the appendix, table III, right. A constant yield stress is assumed for the Epoxy adhesive. 


\subsection{Constitutive Model for Concrete}

\subsubsection{Equation of State}

The concrete equation of state for the pore free matrix material is based on the Mie-Grüneisen form (6a) with a polynomial Hugoniot curve (6c). Herrmann's model [17] describes porosity $\alpha=\rho_{\text {matrix }} / \rho_{\text {porous }}$ as an additional state variable (11a). The compaction path (11b) is defined using the initial porosity $\alpha_{\text {init }}$, pore crush pressure $\mathrm{p}_{\mathrm{el}}$, lockup pressure $\mathrm{p}_{\mathrm{comp}}$ and exponent $\mathrm{N}$. The employed equation of state data is derived from plate impact tests in [31],[32] and specified in table IV.

$$
\mathrm{p}=\mathrm{f}\left(\rho_{\text {matrix }}, \mathrm{e}\right) \stackrel{\text { porous }}{\rightarrow} \mathrm{p}=\mathrm{f}(\rho \alpha, e) \quad \text { with } \alpha=1+\left(\alpha_{\text {init }}-1\right)\left[\frac{\mathrm{p}_{\text {comp }}-\mathrm{p}}{\mathrm{p}_{\text {comp }}-\mathrm{p}_{\text {el }}}\right]^{\mathrm{N}}
$$

\subsubsection{Failure Surface depending on Pressure, Triaxiality and Strain Rate}

The strength model proposed and developed in [30],[31] is inspired by Chen's [5] concept of three limit surfaces in stress space. Figure 2, left, shows the three surfaces describing the elastic limit $\mathrm{Y}_{\mathrm{el}}$, failure $Y_{\text {fail }}$ and residual shear strength $Y_{\text {fric }}$ of the damaged concrete under confined conditions.

$$
\begin{aligned}
& f\left(p, \sigma_{e q}, \theta, \dot{\varepsilon}\right)=\sigma_{e q}-Y_{f a i l}(p, \theta, \dot{\varepsilon})=\sigma_{e q}-Y_{T X C}(p) R_{3}(\theta) F_{\text {Rate }}(\dot{\varepsilon})=0 \\
& Y_{\text {fail }}(p, \theta, \dot{\varepsilon})=Y_{T X C}(p) R_{3}(\theta) F_{\text {Rate }}(\dot{\varepsilon}) \\
& Y_{T X C}^{*}=A \cdot\left(p^{*}-H T L^{\prime^{*}}\right)^{n} \quad \text { for } \quad p^{*} \geq \frac{1}{3} \\
& Y_{T X C}^{*}=0 \quad \text { for } \quad p^{*}<H T L^{*}
\end{aligned}
$$

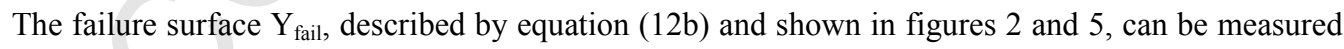
on hydraulic machines with triaxial control, some results are shown in figure 1, right. It is therefore taken as reference to construct all limit surfaces. The compressive meridian $\mathrm{Y}_{\mathrm{TXC}}(\mathrm{p})$ (13) describes the pressure dependence for principal stress conditions $\sigma_{\mathrm{I}}<\sigma_{\mathrm{II}}=\sigma_{\mathrm{III}}$ (tensile stresses defined positive) with parameters A and N. All measures of hydrostatic pressure and the deviatoric strength are normalized over the uniaxial compressive strength $f_{c}$, when denoted with *. Towards low pressures the exponential form is continued by linear interpolations from the uniaxial compressive strength $\left(\sigma^{*}{ }_{\text {eq }}, p^{*}\right)=\left(f_{c} / f_{c}, 1 / 3\right)$ to shear strength 
$\left(\mathrm{f}_{\mathrm{s}} / \mathrm{f}_{\mathrm{c}}, 0\right)$ and uniaxial tensile strength $\left(\mathrm{f}_{\mathrm{t}} / \mathrm{f}_{\mathrm{c}}, \mathrm{f}_{\mathrm{t}} / 3 \mathrm{f}_{\mathrm{c}}\right)$ and extrapolated to the intersection $\mathrm{HTL}^{*}=\mathrm{HTL} / \mathrm{f}_{\mathrm{c}}$ with the hydrostatic axis. The auxiliary variable $\mathrm{HTL}^{, *}$ only occurs in equation (13a) to provide continuity of $\mathrm{Y}^{*}{ }_{\text {TXC }}$ at the uniaxial compressive strength $\left(\sigma^{*}{ }_{\text {eq }}, \mathrm{p}^{*}\right)=\left(\mathrm{f}_{\mathrm{c}} / \mathrm{f}_{\mathrm{c}}, 1 / 3\right)$. Hydrostatic pressures in tension are limited to $\mathrm{HTL}^{*}$ with correction of the internal energy for the release of the tensile pressure portion below $\mathrm{HTL}^{*}$. For such states the deviatoric strength is zero, until pressures above HTL* occur. All above and following input parameters are summarized in the appendix, table III.

Rotation of the compressive meridian around the hydrostatic axis spans the complete failure surface in stress space (figure 2, left). To describe reduced strength on shear and tensile meridians it is multiplied with a factor $\mathrm{Q}_{2} \leq \mathrm{R}_{3}(\theta) \leq 1$ (figure 5 , right). The Lode angle $\theta$ describes stress triaxiality and depends on the third invariant $J_{3}$ of the stress tensor (14b). The dimensionless function $R_{3}$ [40] scales referring to the compressive meridian $Y_{T X C}$ with $R_{3}=1$. The lowest value $Q_{2}>0.5$ is reached on the tensile meridian with principal stresses combined as $\sigma_{\mathrm{I}}>\sigma_{\mathrm{II}}=\sigma_{\mathrm{III}}$. The ratio $\mathrm{Q}_{2}$ of tensile to compressive meridian decreases with increasing pressure (from 0.684 to 0.705 for $1 / 3<\mathrm{p} / \mathrm{f}_{\mathrm{c}}<7 / 3$ ). This effect is called 'brittle to ductile transition' and is described by equation (14c).

$$
\begin{aligned}
R_{3}\left(\theta, Q_{2}\right) & =\frac{2\left(1-Q_{2}^{2}\right) \cos \theta+\left(2 Q_{2}-1\right)\left[4\left(1-Q_{2}^{2}\right) \cos ^{2} \theta+5 Q_{2}^{2}-4 Q_{2}\right]^{\frac{1}{2}}}{4\left(1-Q_{2}^{2}\right) \cos ^{2} \theta+\left(1-2 Q_{2}\right)^{2}} \\
\cos 3 \theta & =\frac{3 \sqrt{3}}{2} \frac{J_{3}}{J_{2}^{3 / 2}}=\frac{27 \operatorname{det}(S)}{2 \sigma_{e q}^{3}} \quad 0.5<Q_{2}=Q_{2,0}+B p^{*} \leq 1
\end{aligned}
$$

The term $\mathrm{F}_{\text {Rate }}(\mathrm{d} \varepsilon / \mathrm{dt})$ in equations $(12 \mathrm{a}, \mathrm{b})$ accounts for the rate enhancement of deviatoric strength. CEB-Bulletin 187 [2] proposes empirical fit functions (15a,b) and (16a,b) for uniaxial tensile and compressive loading. In the model the strain rate influence for hydrostatic pressures above $f_{c} / 3$ is calculated according to (15a), for pressures below $f_{t} / 3$ equation (16a) is applied. Strain rate enhancement factors $F_{\text {Rate }}$ between these limits are linearly interpolated. By this formulation the complete failure surface (14) is radially dilated around the origin $\left(\mathrm{p}=0, \sigma_{\mathrm{eff}}=0\right)$ for higher strain rates, as indicated by the dashed line and square measurement points in figure 5, left. The input parameters for $\alpha$ and $\delta$ are specified in table IV. The units in equations (15) and (16) are [MPa] for $f_{t}$ and $f_{c}$ and [1/s] for strain rates. 
Compression $(15 \mathrm{a}, \mathrm{b})$

$$
\begin{aligned}
& F_{\text {Rate }}=\frac{f_{c d}}{f_{c}}=\left(\frac{\dot{\varepsilon}}{\dot{\varepsilon}_{0}}\right)^{\alpha} \\
& \frac{f_{c d}}{f_{c}}=\gamma \sqrt[3]{\dot{\varepsilon}} \\
& \dot{\varepsilon}_{0}=30 \cdot 10^{-6} s^{-1}, \alpha=\frac{1}{5+3 / 4 f_{c}} \\
& \log \gamma=6 \alpha-0.492 \\
& \dot{\varepsilon}_{0}=3 \cdot 10^{-6} s^{-1}, \delta=\frac{1}{10+\frac{1}{2} f_{c}}
\end{aligned}
$$

Tension $(16 \mathrm{a}, \mathrm{b})$

\subsubsection{Elastic Limit and Hardening}

The initial elastic surface $Y_{\text {elastic }}$ of the virgin material is derived from the failure surface $Y_{\text {fail }}$ using the ratio of elastic tensile and compressive stress over the respective ultimate strength $\left(\mathrm{f}_{\mathrm{t}, \mathrm{el}} / \mathrm{f}_{\mathrm{t}}\right.$ and $\left.\mathrm{f}_{\mathrm{c}, \mathrm{e}} / \mathrm{f}_{\mathrm{c}}\right)$. For pressures below $f_{t, e l} / 3 f_{t}$ the elastic scaling function $F_{\text {elastic }}$ takes the value $f_{t, e l} / f_{t}$. Above $f_{c, e l} / 3 f_{c}$ it is equal to $\mathrm{f}_{\mathrm{c}, \mathrm{e}} / \mathrm{f}_{\mathrm{c}}$. Between these bonds it is linearly interpolated with respect to the pressure. The elastic surface is closed consistently with the porous equation of state (11) towards higher pressures involving pore compaction using a parabolic cap function $\mathrm{F}_{\text {cap }}(17 \mathrm{~b})$. The upper cap pressure $\mathrm{p}_{\mathrm{o}}$ at which deviatoric stresses are reduced to zero starts for the virgin material at $\mathrm{p}_{\mathrm{el}}$. During continued compaction it grows consistently with the current pore compaction pressure of the equation of state. The lower pressure $\mathrm{p}_{\mathrm{u}}$ for cap influence is $\mathrm{f}_{\mathrm{c}} / 3$. Figure 2, right, illustrates the resulting elastic surface.

$$
\begin{aligned}
& Y_{\text {elastic }}=Y_{\text {fail }} F_{\text {elastic }} F_{\text {cap }} \quad F_{C A P}=\left\{\begin{array}{cll}
1 & \text { for } & p \leq p_{u}=f_{c} / 3 \\
\sqrt{1-\left(\frac{p-p_{u}}{p_{o}-p_{u}}\right)^{2}} & \text { for } & p_{u}<p<p_{o} \\
0 & \text { for } & p \geq p_{o}=p_{e l}
\end{array}\right. \\
& Y_{\text {hard }}=Y_{\text {elastic }}+\frac{\varepsilon_{e q}^{p l}}{\varepsilon_{e q}^{p l, h a r d}}\left(Y_{\text {fail }}-Y_{\text {elastic }}\right) \\
& \varepsilon_{e q}^{\text {pl,hard }}=\frac{\left(Y_{\text {fail }}-Y_{\text {elastic }}\right)}{3 G}\left(\frac{G_{\text {elastic }}}{G_{\text {elastic }}-G_{\text {plastic }}}\right)
\end{aligned}
$$


Between the initial elastic surface and the ultimate failure surface hardening is described using equations (18a,b). The loading surface $\mathrm{Y}_{\text {hard }}$ is scaled between $\mathrm{Y}_{\text {elastic }}$ and $\mathrm{Y}_{\text {fail }}$ controlled by the equivalent plastic strain. The plastic stiffness is specified by the input ratio $G_{\text {elastic }} /\left(G_{\text {elastic }}-G_{\text {plastic }}\right)$.

\subsubsection{Damage Evolution and Residual Shear Strength}

When hardening states reach the ultimate strength of the concrete on the failure surface $Y_{\text {fail }}$ damage is accumulated during further inelastic loading controlled by plastic strain. The model by Holmquist and Johnson [19] is taken as basis for the evolution law. Equations (19) and (20) specify how the plastic increments are normalized over the effective strain to failure $\varepsilon_{\mathrm{eq}}^{\mathrm{pl} \text { fail }}$. The effective strain to failure is depending on the hydrostatic pressure $\mathrm{p}$ with the shape parameters $\mathrm{D}_{1}, \mathrm{D}_{2}$ and a lower limit efmin. Contrary to the original paper only deviatoric plastic increments contribute to the damage evolution. Volumetric plastic increments only affect the equation of state and the elastic cap function, a detail not described by Holmquist. The effect of damage is modeled as a loss in deviatoric strength by interpolating as $(21 b)$ between the failure surface $Y_{\text {fail }}$ and residual friction resistance surface $Y_{\text {fric }}(21 a)$. This surface can so far not be measured, this is one aim of the described work. Until this is achieved the same pressure dependence as for the intact limit surface is assumed $(B=A, m=n)$.

$$
\begin{aligned}
& D=\int_{\varepsilon_{e q} p, \text { hard }}^{\varepsilon_{e q}^{p l, \text { fail }}} \frac{1}{\varepsilon_{e q}^{p l, \text { fail }}(p)} d \varepsilon_{\text {eff }}^{p} \stackrel{\text { incremental }}{=} \sum \frac{\Delta \varepsilon_{e q}^{p l}}{\varepsilon_{e q}^{p l, \text { fail }}(p)} \\
& \varepsilon_{e q}^{p l, \text { fail }}\left(p^{*}\right)=D_{1}\left(p^{*}-H T L^{*}\right)^{D_{2}} \geq e \text { fmin } \\
& Y_{\text {fric }}=B \cdot p^{m} \quad Y_{\text {damaged }}=Y_{\text {fail }}+D\left(Y_{\text {fric }}-Y_{\text {fail }}\right)
\end{aligned}
$$

\section{Analysis of Impact Tests}

The analysis of stresses will focus on the first phase of compressive loading under uniaxial strain. Therefore the configuration can be simplified as cylindrical symmetric, which allows very high mesh resolutions in order to resolve the bonding layers with $200 \mu \mathrm{m}$ by one cell size (figure 4, right, 80000 
cells) The whole target configuration is modeled as one domain.

\subsection{Comparison of Assembled against Monolithic Concrete Target}

As a first predictive step, the described numerical modeling approach is used to provide insight to the questions raised in section 2.1 about the influence of the target block structure on experimental measurements. Therefore, the 'assembled' simulation configuration with explicit description of the epoxy adhesive layers by one cell layer of $200 \mu \mathrm{m}$ is compared to one monolithic 'block' of concrete without adhesive. Figure 6, left, shows the comparison of longitudinal stress signals in gauges 1 to 3 for both configurations. The overall agreement is very good. Minor differences occur for times later than $15 \mu \mathrm{s}$ after impact. The agreement in the uniaxial compression and release phase is excellent.

Figure 6, right, depicts the lateral stress calculations in gauge 4. Again we note minor differences between both simulation configurations. For the one-dimensional compression and release phase up to $15 \mu$ differences are negligible with a very small deviation of the second stress step at about 80MPa.

More important is the difference of measuring lateral stresses in positions 4 and 1. For the experimental analysis of concrete shear strength, they shall be assumed congruent, as the distance from the impact phase is identical. However, simulations show that this assumption holds only for the rising of stresses and still for the peak values. Release is different, which is caused by the proximity of the projectile edge and the resulting arrival of the lateral shear release wave. Later on the impactor cylindrical collar is keeping up the compressive stress at gauge 4 more than the flat U-bottom of $25 \mathrm{~mm}$ thickness at the level of gauge 1 . For the analysis of pressure rise and peak values still seems appropriate, but gauge 4 is moved towards the projectile centre line in an improved configuration [41].

Bourne [3] measured differences in failure propagation in glasses when joining two high precision plates to replace one monolithical. The described model predicts that concrete does not show this behavior. Figure 7, left column, compares damage profiles from the impact face into the concrete near the symmetry axis. The early phase of uniaxial compression (upper line) shows no or negligible influence in the damage propagation. It is worthwhile to notice that calculated damage levels of 8.5 to $11 \%$ are very small at this early stage. More deviations occur when later times are considered with various release waves and multiaxial stress and shear states acting on the concrete material. Important deviations are found when analyzing both damage patterns profiles at $80 \mu$ s (figure 7 , lower line). Still, the overall 
damage pattern is similar: A large shear damage zone occurs close to the projectile edge. Localized shear and bending cracks extend into the centre of the target. A distinct spallation plane is formed at 60 to $70 \mathrm{~mm}$ in the concrete target towards the rear surface. At stages later than $120 \mu$ s the target is totally damaged and disrupted.

Summing up, the assembled concrete target with gauges between precisely joined blocks using thin films of epoxy resin is very representative for the behavior of a monolithic target during one-dimensional compression and release. Careful consideration is necessary when analyzing later stress states, especially combining longitudinal measurements on the symmetry axis and lateral measurements off-axis (e.g. gauges 1 and 4$)$.

\subsection{Influence of Gauge Size}

Resolving wave propagation details in concrete can be disturbed from the following sources:

- The heterogeneity of the sample causes internal reflections and strain localizations during stress wave propagation. This problem has been numerically analyzed by Park [29], Riedel [32] and many other authors.

- Large gauge sizes may be necessary to derive significant homogenized state variables for unscaled concrete. This problem is most significant when the gauge extends in the direction of the wave propagation as transverse gauge 4 in the present case.

The size influence of the gauge size is studied by averaging the signal along 1 to 30 cells spread over

0.2 to $6 \mathrm{~mm}$ in figure 8 . Local analysis of lateral stress measurements in only one cell of $0.2 \mathrm{~mm}$ length shows a two wave structure separating at $100 \mathrm{MPa}$ with a time delay of about $0.5 \mu$ s for the following wave. This detail is lost when increasing the gauge size $\mathrm{L}_{\text {gauge. }}$. The minimal resolvable time window can be approximated as the time $t_{\text {res }}=\mathrm{L}_{\text {gauge }} / \mathrm{c}_{\mathrm{P} \text {,wave }}$ the wave front needs to travel across the gauge. For a gauge length of $6 \mathrm{~mm}$ and the compressive wave traveling with $\mathrm{c}_{\mathrm{P}}=2230 \mathrm{~m} / \mathrm{s}$ (see section 3.3 ) wave features down to $t_{\mathrm{res}}=2.7 \mu \mathrm{s}$ can be resolved. This is not sufficient to resolve the small two wave structure in figures 8 and 9.

\subsection{Evaluation of Dynamic Strength, Failure Wave Speed and Strain Rate}

The procedure of evaluating experimental gauge signals is prepared by numerical predictions. As all 
state variables are computed in every cell, assumptions to be taken on measurements signals can be verified. First the interpretation of the wave structures during arrival of the compression wave (figures 6 and 9) is addressed. The elastic and plastic waves separate at 48MPa stresses (I), but the second wave structure (II) at 280MPa longitudinal and $80 \mathrm{MPa}$ lateral stress is of particular interest. In Figure 9 it is clearly associated with the onset of damage at the ultimate strength of the concrete.

The stress state in terms of hydrostatic pressure and equivalent (shear) stress can be evaluated from the longitudinal and transverse stress signals in figure 9, left, using equations (1) and (2). The analysis can be continuously applied across the different limits of elastic loading (I), peak strength (II) and compression of damaged material (III). Plotting as equivalent stress versus hydrostatic pressure (figure 9, right) shows elastic loading and the beginning hardening inside the static failure surface. The peak stress at failure (II) lies outside the static failure surface due to strain rate hardening. After onset of damage the material is further compressed along the dynamic yield surface of the damage material. The ultimate stress state (III) is defined by impact velocities and impedances.

The phase speeds of the different wave portions can be evaluated as in experimental practice: the arrival time and the loading rate are deduced at the point of highest gradient of the wave portion. Figure 10 illustrates the derivation of the longitudinal elastic wave speed $\left(c_{p, \text { elastic }}=4228 \mathrm{~m} / \mathrm{s}\right)$, the wave speed of the intact material at ultimate strength $\left(c_{p, \text { intact }}=2567 \mathrm{~m} / \mathrm{s}\right)$, the damaged $\left(c_{p, \text { fail }}=2229 \mathrm{~m} / \mathrm{s}\right)$ and the release wave speed $\left(c_{\text {rel }}=2000 \mathrm{~m} / \mathrm{s}\right)$, calculated as $c_{p}=\left(x_{2}-x_{1}\right) /\left(t_{2}-t_{1}\right)$.

The longitudinal stress in the damaged material can be read as $637 \mathrm{MPa}$ from the maximum plateau of gauge 1 in figure 10 . Using the momentum equation (22a) the particle velocity can be derived to $140 \mathrm{~m} / \mathrm{s}$. Input into mass conservation (22b) results in a strain of $6.27 \%$ at ultimate compression. Comparing the peak particle velocity deduced from the stress signal to $140 \mathrm{~m} / \mathrm{s}$ and the locally simulated particle velocities in the cells (figure 11 , left, $131 \mathrm{~m} / \mathrm{s}$ ), we note reasonable agreement with a $6.8 \%$ over prediction for the value deduced as in an experiment.

$$
u_{p}=\frac{-\sigma}{\rho_{0} c_{p}} \quad \dot{\varepsilon}=\frac{u_{p}}{c_{p}} \quad \dot{\varepsilon} \cong \frac{\varepsilon}{t_{\text {rise }}} \quad(22 \mathrm{a}, \mathrm{b}, \mathrm{c})
$$

In experimental practice the strain rate will be derived from there by using the rise time of the slope again at the steepest point (see inclined dashed lines in figure 10). In gauge 1 this rise time corresponds to 
$1.75 \mu$ s which leads to a strain rate of $3.58 \times 10^{4} / \mathrm{s}$ when using equation (22c). The rate derived in gauge 2 is very similar with $2.85 \times 10^{4} / \mathrm{s}$. Comparison to local strain rate histories in the simulation cells (figure 11 , right) reveals very good agreement. Interestingly, the highest strain rates are simulated at the elasticplastic transition and near the end of damage evolution.

\subsection{First Experimental Results}

Figure 12, left, shows the experimental measurement ' $A$ ' of the configuration in figures 3 and 4 . Mortar with a maximum grain size of $4 \mathrm{~mm}$ and uniaxial compressive strength of $37.7 \mathrm{MPa}$ is used as a starting point with the perspective to testing full scale concrete in the $200 \mathrm{~mm}$ caliber test facility. Impact velocities were $193 \mathrm{~m} / \mathrm{s}$ in both experiments 'A' and 'B'.

The longitudinal stress signals of gauges 1 to 3 show all decreasing phase velocities of stress wave portions above $210 \mathrm{MPa}$. This observation is very consistent with the simulations and is attributed to different wave speeds across the failure front. The compression wave properties before and after failure evaluated by equations (22) as previously described are given in table I. Both measured and simulated values lie in the large scatter range of available experiments in figure 1 . The differences underline the importance of improved measurements and analysis at the minimum of wave speeds at particle velocities between 30 and $300 \mathrm{~m} / \mathrm{s}$ behind the failure wave.

Figure 12, right, shows experimental measurements ' $\mathrm{B}$ ' with two lateral gauges numbered 4 and 5 at the offsets of the longitudinal gauges 1 and 2, but closer to the impact center. The longitudinal gauges show again the two wave structure which we assign to the onset of damage. The lateral gauges do not display distinctly this feature because of the effective gauge length of $6 \mathrm{~mm}$ along the impact direction (see section 3.2 and figure 8). Nevertheless, the stress tensor can be evaluated in terms of pressure and equivalent stress according to equations (1) and (2). The derived values at ultimate strength (II) under a strain rate of 14350/s and at maximum compression (III) beyond the failure threshold with 23100/s are given in table II. Larger measurement series of such strength measurements at highest strain rates promise unique input data for dynamic concrete models. 


\section{Conclusions}

The present paper describes predictive numerical simulations and first compression and shear stress measurements in concrete materials. The experimental configuration is modeled in a Lagrangian hydrocode together with equation of state and dynamic strength descriptions for concrete developed earlier and summarized in section 2 . The simulations predict that thoroughly assembled targets with integrated gauges are representative for monolithic concrete samples, especially during the loading phase of a planar shock wave. The numerical analysis furthermore supports derivation of stress wave and particle velocities, strains and strain rates from time-resolved stress measurements.

Decreasing phase velocities for compression wave portions above 200 to $300 \mathrm{MPa}$ are observed both in simulations and first experiments. Based on the model, the slower wave portions can be clearly attributed to the onset of damage and thus the material strength at high strain rates of $25000 / \mathrm{s}$. It is experimentally confirmed by first experiments on mortar, further justification and extension to full scale concrete has to follow. For this purpose guidelines for the gauge size influence are given by numerically analyzing highlighting to the rule of thumb $\mathrm{t}_{\mathrm{res}}=\mathrm{L}_{\text {gauge }} / \mathrm{c}_{\mathrm{P} \text {,wave. }}$.

In the proposed configuration the triaxial strength is measured at a strain rate of 5000-15000/s at hydrostatic pressures from 70 to $140 \mathrm{MPa}$ and deviatoric stresses from 70 to $130 \mathrm{MPa}$. Higher stresses may be reached by impact velocities exceeding $200 \mathrm{~m} / \mathrm{s}$ in near future.

The technique can furthermore provide valuable data on the yield surface of damaged concrete at strain rates of about 25000/s. This is currently a major lack for dynamic concrete models in hydrocodes. Signal predictions and first measurements analyze the damaged strength surface up to $250 \mathrm{MPa}$ of hydrostatic and 400MPa equivalent stress at a strain rates of $3 \times 10^{4} / \mathrm{s}$. Further measurements with more data, detailed evaluation and transition to full scale concrete are very promising perspectives.

\section{Acknowledgements}

The described work results from cooperation of Tokyo Institute of Technology, Materials and Structures Laboratory and the Ernst-Mach-Institute of Fraunhofer Society, Germany. The author is grateful for the assignment at TokyoTech, which made the numerical study possible. Our special thanks are due to Dr. Katayama, Itochu Technical Solutions Corporation, Japan, for his continued support of the scientific exchange and work. We furthermore thank Mr. Hasegawa for his valuable work in constructing 
the test configuration.

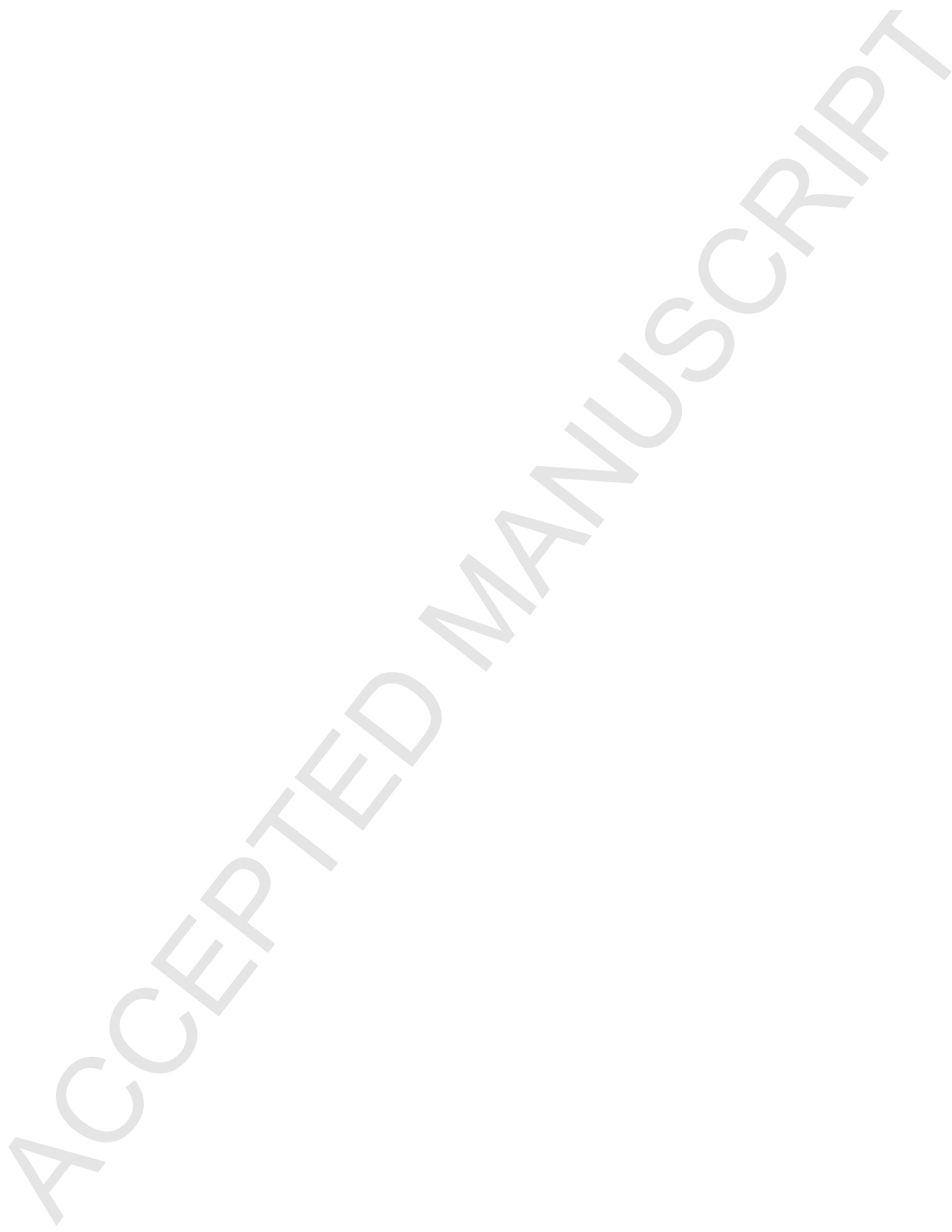




\section{References}

[1] Bischoff P.H.: Materials \& Structures, RILEM, 24, 1999, 425-450.

[2] Bischoff P.H., Schlüter F.-H. (Ed.): Concrete structures under impact and impulsive loading, Synthesis Report. Comité Euro-Internationale du Beton, Bulletin d'information No. 187, Dubrovnik, September 1988.

[3] Bourne N., Millet J., Rosenberg Z., Murray N., J. Mech. Phys. Solids, 46, 10 (1998), 1887-1908.

[4] Brar NS, Bless SJ, Rosenberg Z., Appl. Phys. Lett. 59 (1991), 3396-3398.

[5] Chen W.F.: Plasticity in Reinforced Concrete. McGraw Hill, New York, 1982. - ISBN 0-07010687-8.

[6] Clifton RJ, Analysis of failure waves in glasses, Appl. Mech. Rev, 46 (1993) 540.

[7] Espinosa HD, Xu Y, Brar NS, J. Am. Ceram. Soc., 80 (1997), 2061.

[8] Espinosa HD, Xu Y, Brar NS, J. Am. Ceram. Soc., 80 (1997), 2074.

[9] Gebbeken N.,Greulich S., Pietzsch A., Int Jn Impact Engineering 32 (2006) 2017-2031.

[10] Gebbeken N., Ruppert M., Arch Appl Mech 70 (2000), 463-78.

[11] Grady DE, Furnish MD, Shock Compression of Condensed Matter (1989) 621-623.

[12] Grady D.E., Impact Compression Properties of Concrete, $6^{\text {th }}$ Int. Symposium on Interaction of Nonnuclear Munitions with Structures, Panama City, Florida, May 3-7, 1993.

[13] Grady D.E., Dynamic Decompression Properties of Concrete from Hugoniot States - 3 to 25 GPa, Experimental Impact Physics Department, Technical Memorandum TMDG0396, Feb. 1996.

[14] Gregson, V.R., A Shock Wave Study of Fondu-Fyre WA-1 and Concrete, General Motors Materials and Structures Laboratori, Report MSL-70-30, 1971.

[15] Grote D.L., Park S.W., Zhou M., Int. Jn. Impact Eng., 25, 869-886, 2001.

[16] Grote DL, Park SW, Zhou M. Jn Appl Physics, 89 (2001), 2115-2123.

[17] Hanchak S.J., Forrestal M.J.: Int J Imp Eng, 12, 1 (1992), 1-7.

[18] Herrmann W., Jn Appl Physics, 40, 6 (1969) 2490-2499.

[19] Holmquist T.J., and Johnson G.R., A computational constitutive model for concrete subjected to large strains, high strain rates, and high pressures, $14^{\text {th }}$ International Symposium on Ballistics, Québec, 1993.

[20] Itho M, Katayama M., Mitake S., Niwa N., Beppu M., Ishikawa N., Numerical study on impulsive local damage of reinforce concrete structures, Proc. Structures under Shock and Impact, Cambridge, 2000.

[21] Ishiguchi M., Yoshida M., Nakayama Y., Matsumura T., Takahashi I., Miyake A., Ogawa T., A study of the Hugoniot of mortar, Journal of Japan Explosives Society, Kayaku Gakkaishi, 61, 6 (2000), 249-253.

[22] Kanel GI, Rasorenov SV, Fortov VE. Shock Compression of Condensed Matters, (1991) 451-454.

[23] Klepaczko JR, Bara A., Int J Impact Eng 25 (2001) 387-409.

[24] Kipp M.E., Lalit, Chhabildas C., CP 429, Shock Compression of Condensed Matter (1997) 557560.

[25] Malvar L.J., Crawford J.E., Wesevich J.W., Simons D., Int Jn Impact Eng 19 (1997) 847-873.

[26] Millet JCF, Bourne NK, Rosenberg Z. CP505, Shock Compression of Condensed Matter, (1999) 607-610.

[27] N.N., AUTODYN, Theory Manual, Century Dynamics Ltd. Horsham, UK, 2003.

[28] Ockert J., Ein Stoffgesetz für die Schockwellenausbreitung von Beton, Dissertation TH Karlsruhe, 1997.

[29] Park S.W., Xia Q., Zhou M. Int J Imp Eng, 25 (2001) 887-910.

[30] Riedel W., Thoma K., Hiermaier S., Schmolinske E. Penetration of Reinforced Concrete by BETAB-500. Proc. 9. ISIEMS, Berlin Strausberg, Mai 1999.

[31] Riedel W., Beton unter dynamischen Lasten - Meso- und Markomechanische Modelle, Ed. ErnstMach-Institut Freiburg, Fraunhofer IRB 2004, ISBN 3-8167-6340-5, http://www.irbdirekt.de/irbbuch/.

[32] Riedel W., Wicklein M., Thoma K., Shock Properties of Conventional and High Strength Concrete, Experimental and Mesomechanical Analysis, Int Jn Impact Engineering 35 (2008) 155-171.

[33] Schuler H., Mayrhofer Chr., Thoma K., Int. Jn. Impact Eng. 32 (2006) 1635-1650.

[34] Steinberg D.J., Cochran SG, Guinan MW, J Appl Phys, 51, 3 (1980).

[35] Steinberg D.J., Equation of State and Strength Properties of Selected Materials, LLNL. Feb 1991 
[36] Tsembelis K, Millett JCF, Proud WG, Field JE. CP505, Shock Compression of Condensed Matter (1999) 1267-1270.

[37] Tsembelis K, Proud WG, Field JE., CP620, Shock Compression of Condensed Matter (2001) 14141417.

[38] Tsembelis K, Proud WG, Willmott GR, Cross DLA, CP706, Shock Compression of Condensed Matter (2003) 1488-1491.

[39] Tsembelis K, Proud WG, Shock Compression of Condensed Matter, AIP (2005) 1496-1499.

[40] Willam K.J., Warnke E.P.: Constitutive Model for the Triaxial Behaviour of Concrete. Int Assoc Bridge Struct Eng, Seminar on Concrete Structure Subjected to Triaxial Stresses, IABSE Proc. 19, Italy, 1975.

[41] Kawai N., Inoue K., Misawa S., Riedel W., Tanaka K., Hayashi S., Kondo K., The dynamic behavior of mortar und impact loading, AIP-CP955, Eds. M. Elert, M. Furnish, R. Chau, N. Holmes, J. Nguyen, Shock-Compression of Condensed Matter, SCCM-07 (2007) 


\section{Tables}

Table I. Compression wave properties, derived from experiments A and B using equations (22) on gague signals 1 and 2.

\begin{tabular}{lcccc}
\hline experiment / time & $\begin{array}{c}\text { wave velocity } \mathrm{c}_{\mathrm{p}} \\
(\mathrm{m} / \mathrm{s})\end{array}$ & $\begin{array}{c}\text { particle velocity } \mathrm{u}_{\mathrm{p}} \\
(\mathrm{m} / \mathrm{s})\end{array}$ & $\begin{array}{c}\text { comp. strain } \\
(-)\end{array}$ & $\begin{array}{c}\text { strain rate } \\
(1 / \mathrm{s})\end{array}$ \\
\hline A, at ultimate strength & 3623 & 26.1 & 0.00719 & 5490 \\
B, at ultimate strength & 2810 & 37.1 & 0.0132 & 14350 \\
A, damaged & 1730 & 153 & 0.0888 & 28500 \\
B, damage & 1610 & 140 & 0.0865 & 23100 \\
\hline
\end{tabular}

Table II. Experimental concrete pressure and strength during impact.

\begin{tabular}{lcccc}
\hline position / time & $\begin{array}{c}\text { longitudinal stress } \\
(\mathrm{MPa})\end{array}$ & $\begin{array}{c}\text { lateral stress } \\
(\mathrm{MPa}\end{array}$ & $\begin{array}{c}\text { pressure } \\
(\mathrm{MPa})\end{array}$ & $\begin{array}{c}\text { equivalent stress } \\
(\mathrm{MPa})\end{array}$ \\
\hline 1, at ultimate strength & 225 & 96,6 & 139 & 128 \\
2, at ultimate strength & $(122)$ & 49 & $(73)$ & $(73)$ \\
1, failed & 487 & 133 & 251 & 354 \\
2, failed & $(482)$ & $(65)$ & $(197)$ & $(397)$ \\
\hline
\end{tabular}

Table III.

Equation of state and strength parameters to describe the A12024-T4 projectile and the Epoxy adhesive.

\begin{tabular}{llll}
\hline & \multicolumn{2}{c}{ A12024-T4 [34][35] } \\
\hline Equation of State & Shock & Shear Modulus & $2.86000 \mathrm{E}+07(\mathrm{kPa})$ \\
Reference density & $2.78500 \mathrm{E}+00\left(\mathrm{~g} / \mathrm{cm}^{3}\right)$ & Yield Stress & $2.60000 \mathrm{E}+05(\mathrm{kPa})$ \\
Gruneisen coefficient & $2.00000 \mathrm{E}+00(-)$ & Maximum Yield Stress & $7.60000 \mathrm{E}+05(\mathrm{kPa})$ \\
Parameter C & $5.32800 \mathrm{E}+03(\mathrm{~m} / \mathrm{s})$ & Hardening Constant & $3.10000 \mathrm{E}+02(-)$ \\
Parameter S & $1.33800 \mathrm{E}+00(-)$ & Hardening Exponent & $1.85000 \mathrm{E}-01(-)$ \\
Reference Temperature & $3.00000 \mathrm{E}+02(\mathrm{~K})$ & Derivative dG/dP & $1.86470 \mathrm{E}+00(-)$ \\
Specific Heat & $8.63000 \mathrm{E}+02(\mathrm{~J} / \mathrm{kgK})$ & Derivative dG/dT & $-1.76200 \mathrm{E}+04(\mathrm{kPa})$ \\
Melting Temperature & $1.22000 \mathrm{E}+03(\mathrm{~K})$ & Derivative dY/dP & $1.69500 \mathrm{E}-02(-)$ \\
\hline \multicolumn{2}{c}{ Epoxy } & Adhesive \\
\hline Equation of State & Polynomial & Shear Modulus & $4.08000 \mathrm{E}+06(\mathrm{kPa})$ \\
Reference density & $\left.1.18600 \mathrm{E}+00(\mathrm{~g} / \mathrm{cm})^{3}\right)$ & Yield Stress & $4.00000 \mathrm{E}+04(\mathrm{kPa})$ \\
Bulk Modulus A1 & $8.83900 \mathrm{E}+06(\mathrm{kPa})$ & & \\
Parameter A2 & $1.75500 \mathrm{E}+07(\mathrm{kPa})$ & Eq. Plastic Failure Strain & $3.00000 \mathrm{E}+00(-)$ \\
Parameter A3 & $1.51600 \mathrm{E}+07(\mathrm{kPa})$ & Reference Temperature & $2.93000 \mathrm{E}+02(\mathrm{~K})$ \\
Parameter B0 & $1.13000 \mathrm{E}+00(-)$ & & \\
Parameter B1 & $1.13000 \mathrm{E}+00(-)$ & & \\
\hline
\end{tabular}

Table IV. Employed material data for 37.7 MPa concrete, AUTODYN [27] input to 'RHT concrete'.

\begin{tabular}{|c|c|c|c|}
\hline Equation of State & P alpha & Tens./Comp. Meridian Ratio (Q) & $6.80500 \mathrm{E}-01$ (none ) \\
\hline Reference density & $2.75000 \mathrm{E}+00$ & Brittle to Ductile Transition & $1.05000 \mathrm{E}-02$ (none) \\
\hline Porous density & $2.16000 \mathrm{E}+00(\mathrm{~g} / \mathrm{cm} 3)$ & G (elas.)/(elas.-plas.) & $2.00000 \mathrm{E}+00($ none $)$ \\
\hline Porous soundspeed & $2.92000 \mathrm{E}+03(\mathrm{~m} / \mathrm{s})$ & Elastic Strength / ft & $7.00000 \mathrm{E}-01$ (none) \\
\hline Initial compaction pressure & $2.51000 \mathrm{E}+04(\mathrm{kPa})$ & Elastic Strength / fc & $5.30000 \mathrm{E}-01$ (none) \\
\hline Solid compaction pressure & $6.00000 \mathrm{E}+06(\mathrm{kPa})$ & Fractured Strength Constant B & $1.60000 \mathrm{E}+00($ none $)$ \\
\hline Compaction exponent & $3.00000 \mathrm{E}+00$ (none ) & Fractured Strength Exponent $\mathrm{m}$ & $6.10000 \mathrm{E}-01$ (none ) \\
\hline Solid EOS & Polynomial & Comp. Strain Rate Exp. Alpha & $3.20000 \mathrm{E}-02$ (none ) \\
\hline Bulk Modulus A1 & $3.52700 \mathrm{E}+07(\mathrm{kPa})$ & Tensile Strain Rate Exp. Delta & $3.60000 \mathrm{E}-02$ (none) \\
\hline Parameter A2 & $3.95800 \mathrm{E}+07(\mathrm{kPa})$ & Failure & RHT Concrete \\
\hline Parameter A3 & $9.04000 \mathrm{E}+06(\mathrm{kPa})$ & Damage Constant, D1 & $4.00000 \mathrm{E}-02$ (none ) \\
\hline Parameter $\mathrm{B} 0=\Gamma$ & $1.22000 \mathrm{E}+00($ none $)$ & Damage Constant, D2 & $1.00000 \mathrm{E}+00($ none $)$ \\
\hline Parameter B1 $=\Gamma$ & $1.22000 \mathrm{E}+00($ none $)$ & Minimum Strain to Failure & $1.00000 \mathrm{E}-02$ (none ) \\
\hline Reference Temperature & $3.00000 \mathrm{E}+02(\mathrm{~K})$ & Residual Shear Modulus Fraction & $1.30000 \mathrm{E}-01$ (none ) \\
\hline Specific Heat & $6.54000 \mathrm{E}+02(\mathrm{~J} / \mathrm{kgK})$ & Tensile Failure & Hydro (Pmin) \\
\hline Compaction Curve & Standard & Erosion & Geometric Strain \\
\hline Strength & RHT Concrete & Erosion Strain & $2.00000 \mathrm{E}+00$ (none ) \\
\hline Shear Modulus & $1.67000 \mathrm{E}+07(\mathrm{kPa})$ & Tens./Comp. Meridian Ratio $\left(\mathrm{Q}_{2,0}\right)$ & $6.80500 \mathrm{E}-01$ (none) \\
\hline Compressive Strength (fc) & $3.77000 \mathrm{E}+04(\mathrm{kPa})$ & Brittle to Ductile Transition B & $1.05000 \mathrm{E}-02$ (none ) \\
\hline Tensile Strength $(\mathrm{ft} / \mathrm{fc})$ & $1.00000 \mathrm{E}-01$ (none ) & & \\
\hline Shear Strength $(\mathrm{fs} / \mathrm{fc})$ & $1.80000 \mathrm{E}-01$ (none) & & \\
\hline $\begin{array}{l}\text { Intact Failure Surface } \\
\text { Constant A }\end{array}$ & $1.60000 \mathrm{E}+00$ (none ) & & \\
\hline $\begin{array}{l}\text { Intact Failure Surface } \\
\text { Exponent } \mathrm{n}\end{array}$ & $6.10000 \mathrm{E}-01$ (none ) & & \\
\hline
\end{tabular}




\section{Figure Captions}

Fig. 1. Left: Shock properties of concrete showing a decisive minimum in stress propagation speed at $\mathrm{u}_{\mathrm{p}}=250 \mathrm{~m} / \mathrm{s}$. Data 'Riedel 03 Conventional' [31] used in section 3 and 4. Right: Static distortional strength as a function of pressure.

Fig. 2. Three surface concept for the concrete strength with hardening, failure and residual friction resistance.

Fig. 3. Experimental configuration of single stage accelerator and concrete sample at TokyoTech.

Fig. 4. Sample geometry with concrete block structure containing longitudinal and transverse gauges. Cylindrical symmetric model of impactor and concrete sample. Mesh resolution of $0.2 \mathrm{~mm}$ describing the adhesive layer for assembled sample.

Fig. 5. Definition of the failure surface by the compressive meridian and the deviatoric section. Data, e.g. by [17].

Fig. 6. Comparing simulated stress signals in block assembled (light colours) with monolithic target (strong colours). Comparison of lateral measurement in gauge positions 4 and 1.

Fig. 7. Damage plots at $15 \mu$ s (scaling 0 to 0.1 ) and $80 \mu$ s (scaling 0 to 1.0). Comparison of assembled target (middle) and monolithic concrete block (right) shows good agreement.

Fig. 8. Influence of effective gauge size for measurement of lateral stress in position 4.

Fig. 9. Damage initiation and associated wave structure in axial and lateral stress profiles (only rise shown). Right: Derived dynamic strength data of from (simulated) longitudinal and transverse stress measurements.

Fig. 10. Evaluation of wave speeds in elastic regime, at ultimate strength and damaged. Slope for evaluation of strain rate of shock wave.

Fig. 11. Peak particle velocities and strain rates evaluated from stress signals compared to continuous signal from simulation.

Fig. 12. First experimental measurements of stress signals using mortar samples. Longitudinal stress signals indicated a failure wave in experiment 'A', left. Successful lateral measurements in experiment 'B', right, allow strength analysis in table II. 


\section{Figures}
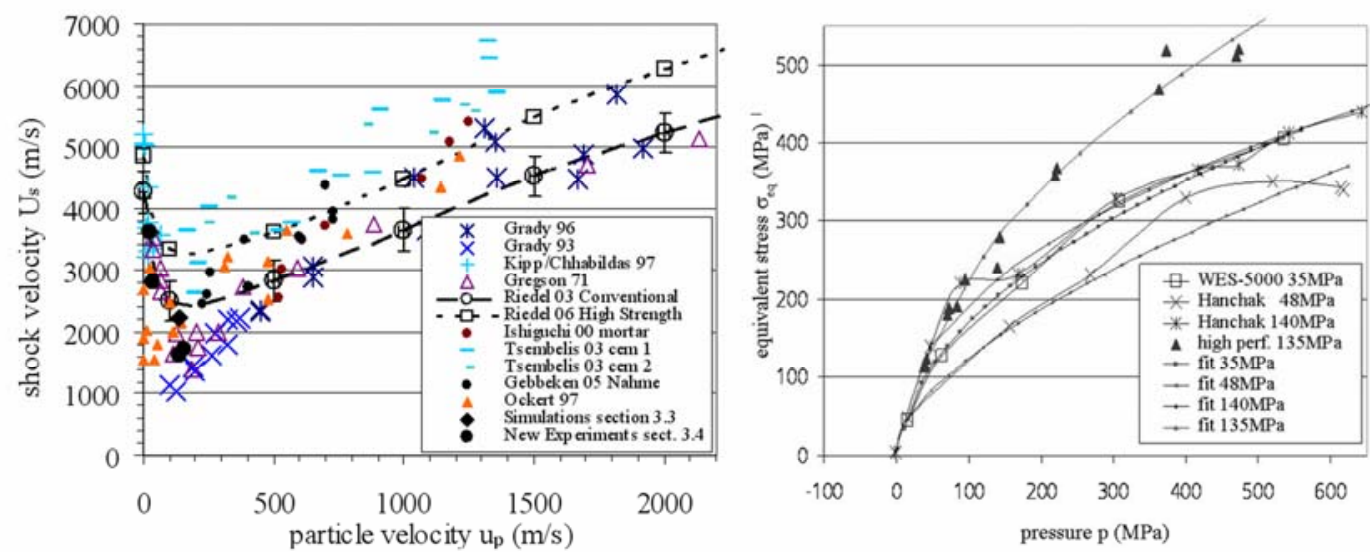

Fig. 1. Left: Shock properties of concrete showing a decisive minimum in stress propagation speed at $\mathrm{u}_{\mathrm{p}}=250 \mathrm{~m} / \mathrm{s}$. Data 'Riedel 03 Conventional' [31] used in section 3 and 4. Right: Static distortional strength as a function of pressure.
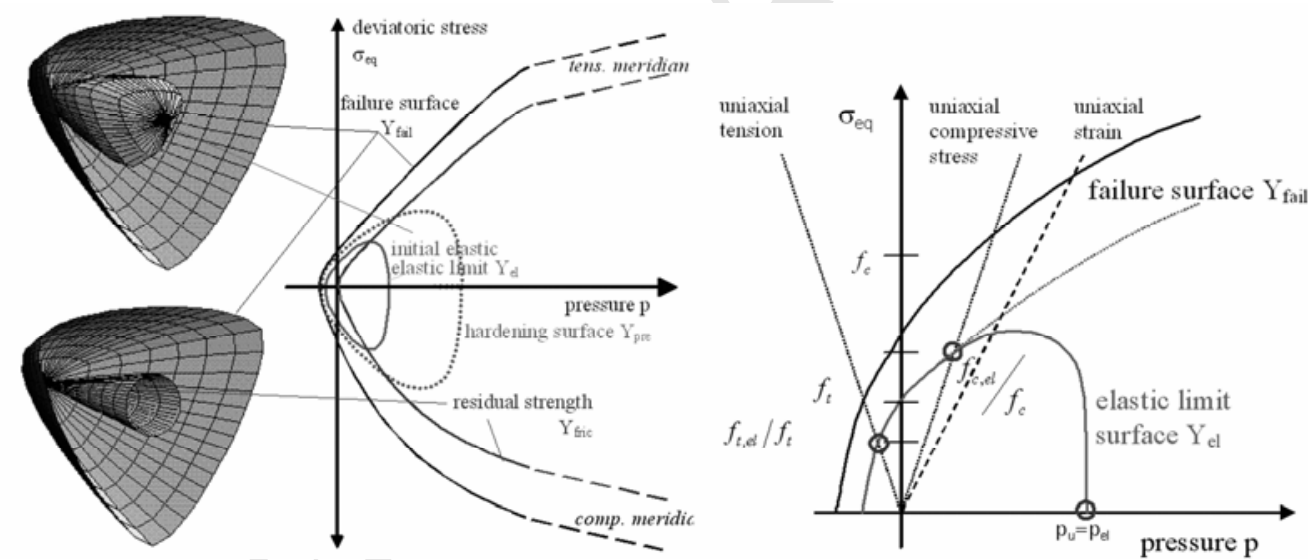

Fig. 2. Three surface concept for the concrete strength with hardening, failure and residual friction resistance.
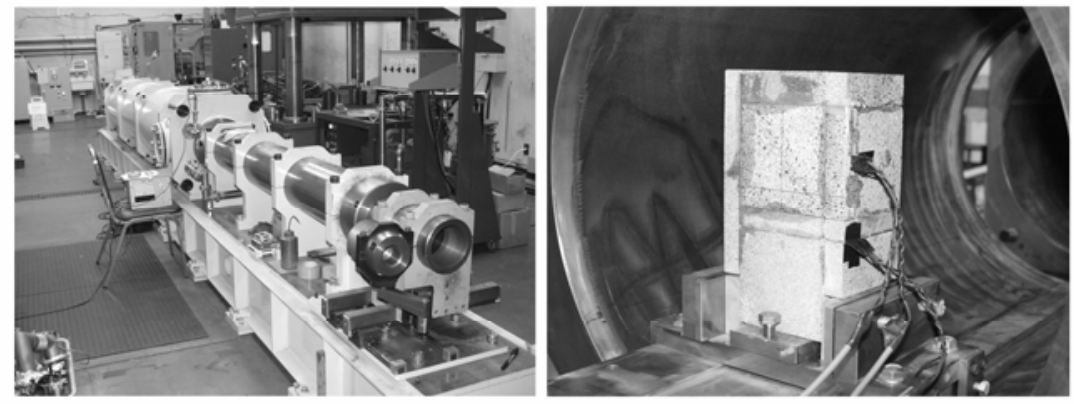

Fig. 3. Experimental configuration of single stage accelerator and concrete sample at TokyoTech. 

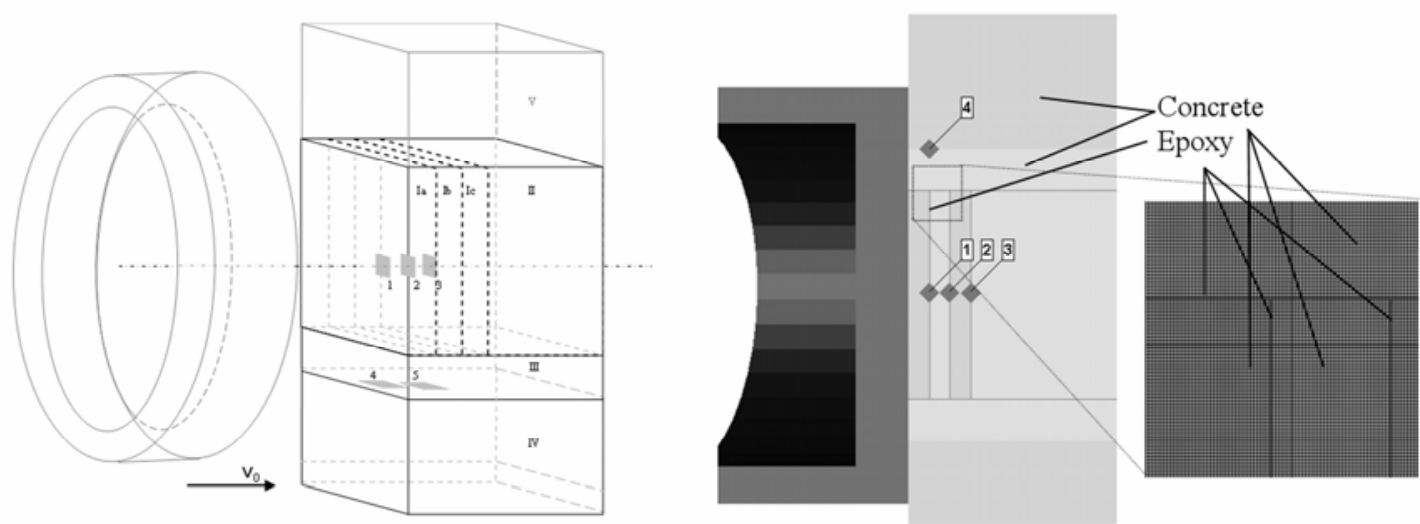

Fig. 4. Sample geometry with concrete block structure containing longitudinal and transverse gauges. Cylindrical symmetric model of impactor and concrete sample. Mesh resolution of $0.2 \mathrm{~mm}$ describing the adhesive layer for assembled sample.
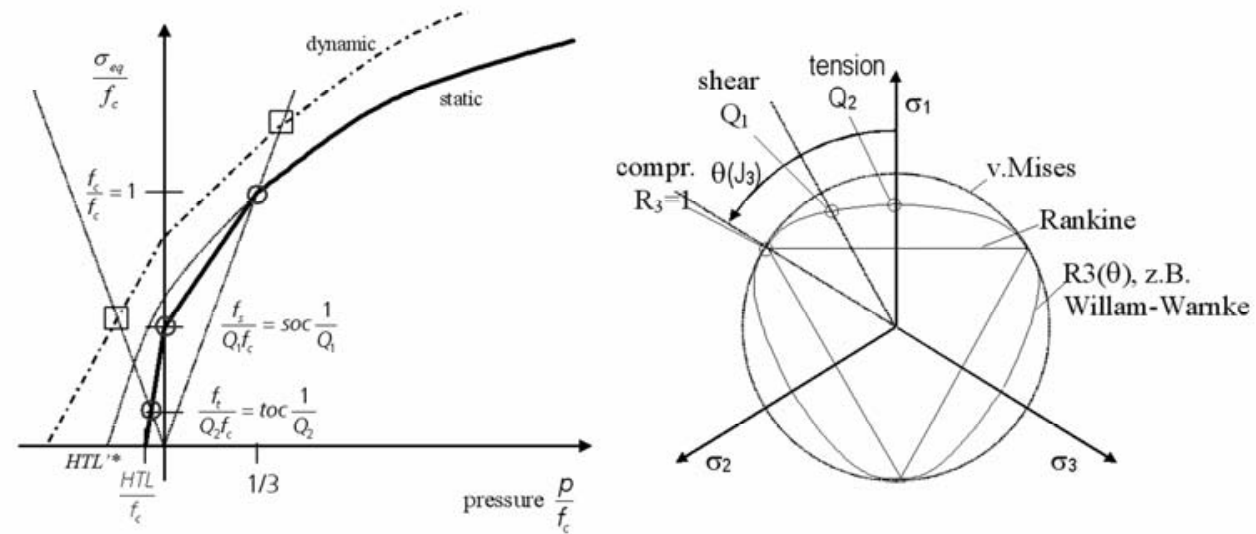

Fig. 5. Definition of the failure surface by the compressive meridian and the deviatoric section. Data, e.g. by [17].
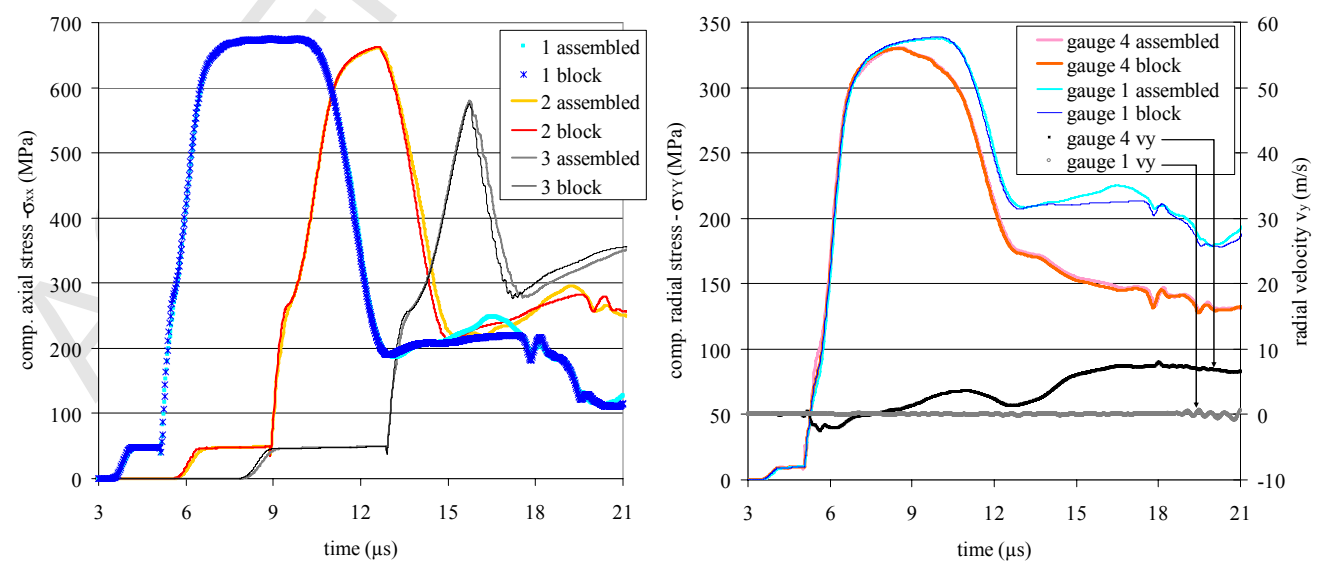

Fig. 6. Comparing simulated stress signals in block assembled (light colours) with monolithic target (strong colours). Comparison of lateral measurement in gauge positions 4 and 1. 

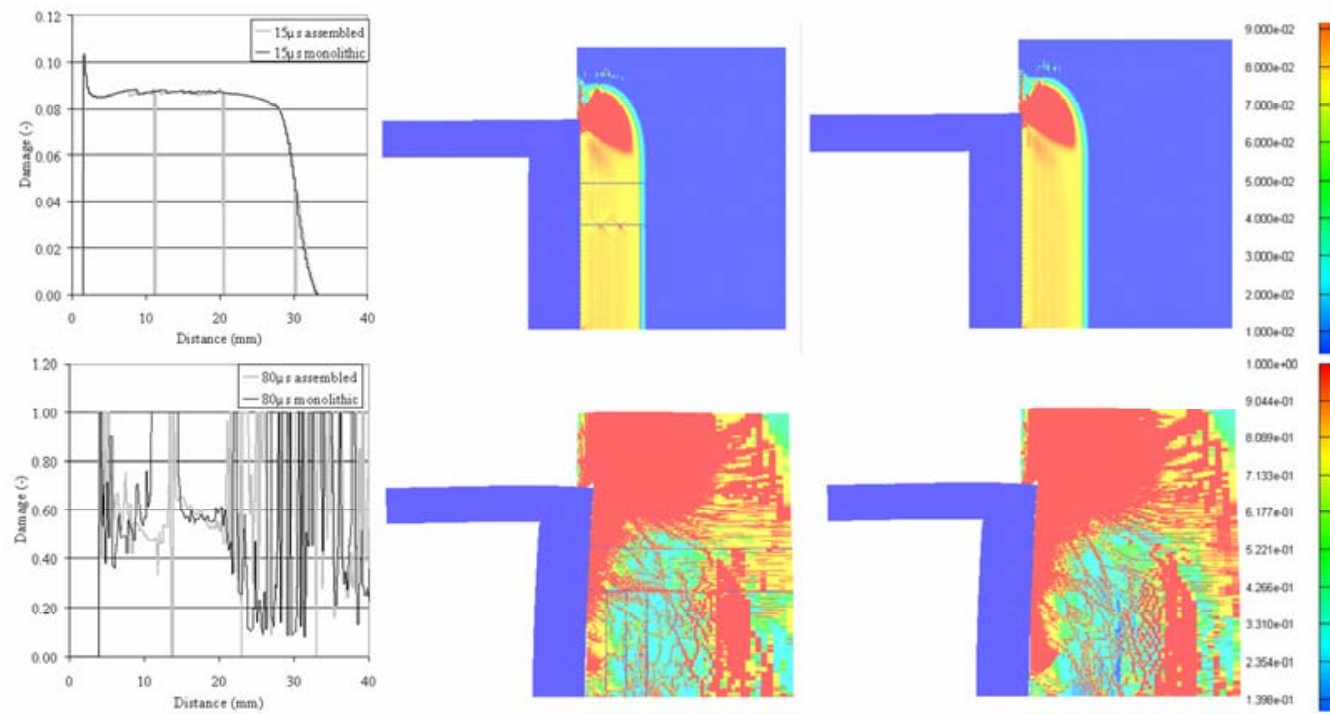

Fig. 7. Damage plots at $15 \mu \mathrm{s}$ (scaling 0 to 0.1 ) and $80 \mu \mathrm{s}$ (scaling 0 to 1.0 ). Comparison of assembled target (middle) and monolithic concrete block (right) shows good agreement.
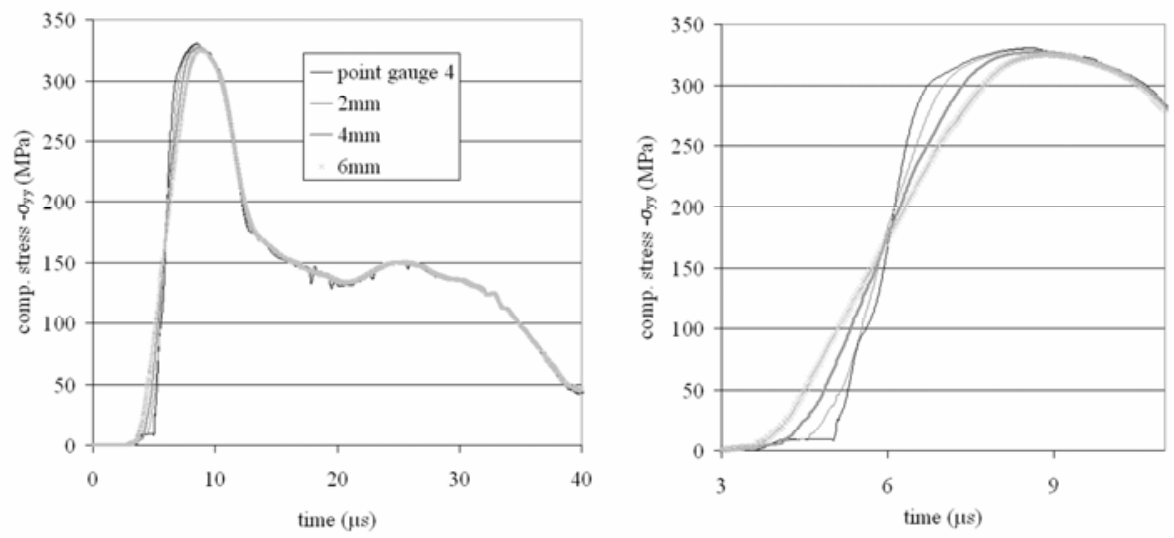

Fig. 8. Influence of effective gauge size for measurement of lateral stress in position 4.
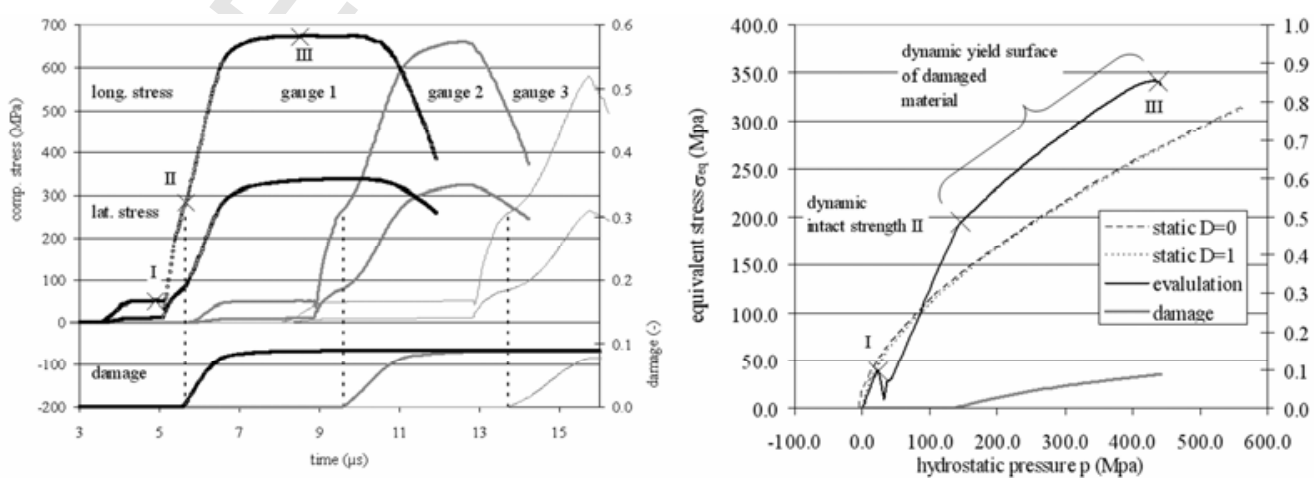

Fig. 9. Damage initiation and associated wave structure in axial and lateral stress profiles (only rise shown). Right: Derived dynamic strength data of from (simulated) longitudinal and transverse stress measurements. 


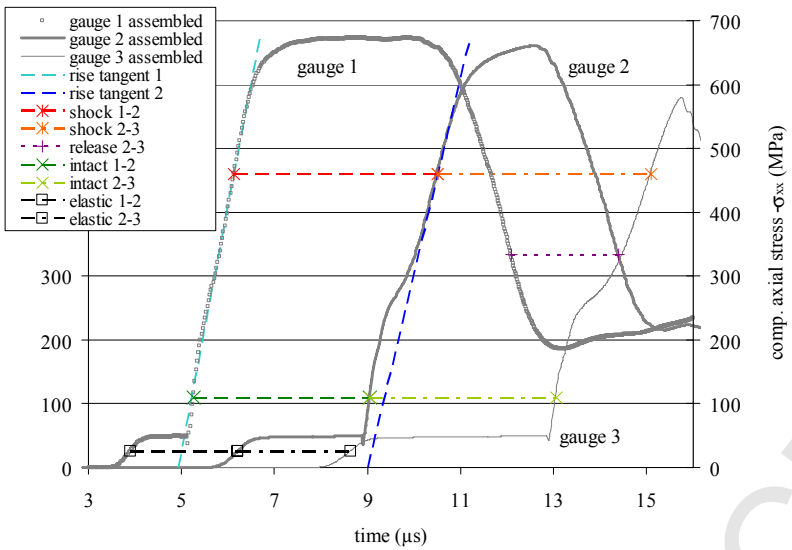

Fig. 10. Evaluation of wave speeds in elastic regime, at ultimate strength and damaged. Slope for evaluation of strain rate of shock wave.
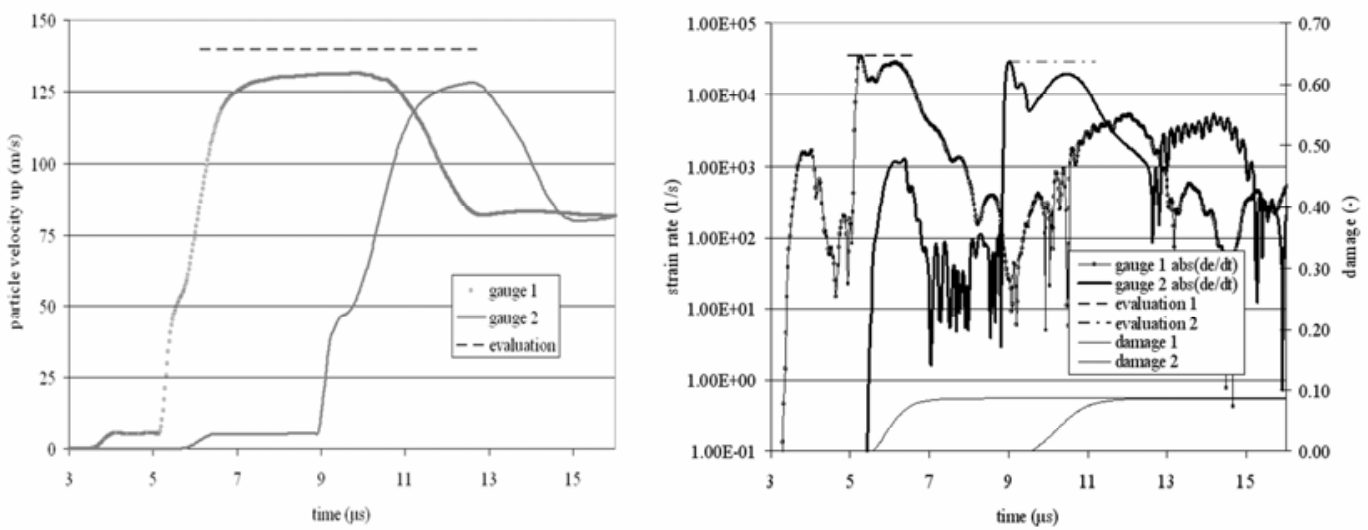

Fig. 11. Peak particle velocities and strain rates evaluated from stress signals compared to continuous signal from simulation.
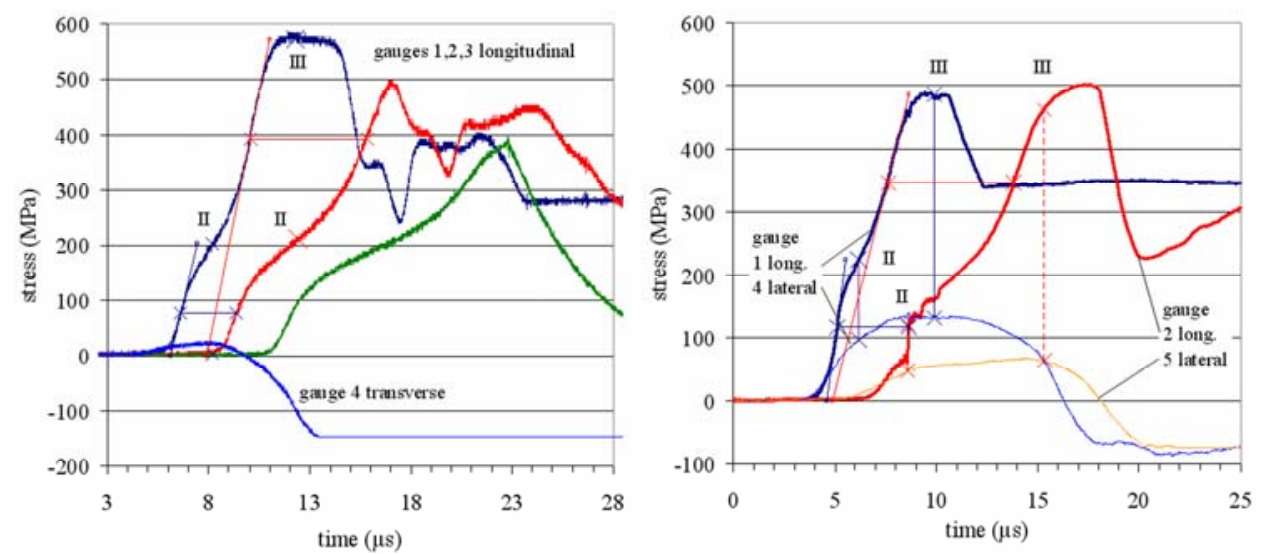

Fig. 12. First experimental measurements of stress signals using mortar samples. Longitudinal stress signals indicated a failure wave in experiment 'A', left. Successful lateral measurements in experiment 'B', right, allow strength analysis in table II. 